\title{
High Gain Non Isolated DC-DC Step-up Converters Integrated with Active and Passive Switched Inductor Networks
}

\author{
M. Al Mamun', Golam Sarowar², Md. Ashraful Hoque ${ }^{3}$, Mehedi Azad Shawon ${ }^{4}$ \\ ${ }^{1}$ Department of Information and Communication Technology, Bangladesh University of Professionals, Bangladesh \\ ${ }^{2,3}$ Departement of Electrical and Electronic Engineering, Islamic University of Technology, Bangladesh \\ ${ }^{4}$ Departement of Electrical and Electronic Engineering, Southeast University, Bangladesh
}

\begin{tabular}{l} 
Article Info \\
\hline Article history: \\
Received Oct 6, 2017 \\
Revised Jan 23, 2018 \\
Accepted Feb 6 2018 \\
\hline
\end{tabular}

\section{Keyword:}

DC-DC converter

Duty cycle

High gain

Non isolated converter

Step up converter

Switched inductor network

\begin{abstract}
High gain dc-dc step up converters have been used in renewable energy systems, for example, photovoltaic grid connected system and fuel cell power plant to step up the low level dc voltage to a high level dc bus voltage. If the conventional boost converter is to meet this demand, it should be operated at an extreme duty cycle (duty cycle closes to unity), which will cause electromagnetic interference, reverse recovery problem and conduction loss at the power switches. This paper proposes a class of non-isolated dc-dc step up converters which provide very high voltage gain at a small duty cycle (duty cycle $<0.5$ ). Firstly, the converter topologies are derived based on active switched inductor network and combination of active and passive switched inductor networks; secondly, the modes of operation of proposed active switched inductor converter and combined active and passive switched inductor converter are illustrated; thirdly, the performance of the proposed converters are analyzed mathematically in details and compared with conventional boost converter and other related researches. Finally, the analysis is verified by simulation results.
\end{abstract}

Copyright (c) 2018 Institute of Advanced Engineering and Science. All rights reserved.

Corresponding Author:

M. Al Mamun,

Departement of Information and Communication Technology,

Bangladesh University of Professionals,

Mirpur Cantonment, Dhaka-1216, Bangladesh.

Email: mamuniut09@gmail.com

\section{INTRODUCTION}

The demand for energy is increasing with the development of society. The use of fossil fuels (coal, oil, gas etc.) to meet this growing demand has affected the environment adversely by causing environmental pollution and greenhouse effect. Moreover, the storage of fossil fuels in the earth is decreasing day by day due to its increased usage. Hence, the necessity of new, clean and renewable energy has emerged greatly to replace the traditional fossil fuel energy. Power generation by photovoltaic (PV) and fuel cell systems have shown good signs of future success as they have been applied on a broad scale [1]-[6].

However, the output voltages of PV and fuel cells range between $20 \mathrm{~V}$ to $40 \mathrm{~V}$ which is very low. A typical fuel cell power plant [7] is depicted in Figure 1. To maintain the line voltage of $220 \mathrm{~V}$ in a single phase system, the grid-connected inverter needs the dc bus voltage at $380 \mathrm{~V}$ which is approximately 20 times the fuel cell output voltage. Thus, a dc-dc step up converter with a very high voltage gain is needed to boost the outputs of PV and fuel cells. To accomplish this, the conventional boost converter must operate at extreme duty cycle (duty cycle closes to unity) which leads to electromagnetic interference, reverse recovery problem, high conduction loss at the switches etc.

Different isolated and non-isolated topologies have been developed to obtain high gain at low duty cycle. Isolated converters involve transformer where the turns ratio of the transformer is adjusted so that a high gain is obtained [8]-[12]. However, a large turn ratio leads to a large leakage inductance which causes 
high voltage spike across the switches [13]-[15]. Besides, isolated converters becomes costly due to its multistage AC/DC/AC conversion and isolated sensors and controllers.

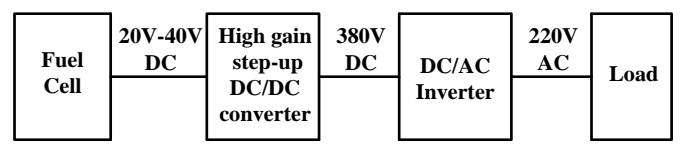

Figure 1. Fuel cell power plant with different power stages

The existing non-isolated converters are normally of coupled inductor type and non-coupled type. The coupled inductor converters adjust the output voltage gain by controlling the turns ratio of the coupled inductor which is similar to the isolated converters [16]-[19]. Thus, the leakage inductance and, as a consequence, the voltage spike across the switches do exist prominently. The non-coupled inductor converters can minimize this issue by removing the magnetic components with a comparatively high voltage gain [20]-[23]. High voltage gain is also achieved in cascaded converter but it offers large and complex circuitry. The transformer less converter in [24] can provide a high voltage gain with reduced voltage stress across the switches. However, the gain is not that much high to achieve $20 \mathrm{~V} / 380 \mathrm{~V}$ conversion at low duty cycle.

Researchers have developed different switched inductor and switched capacitor networks to increase the voltage level [24]. Series and parallel connections of these networks make it possible to obtain higher voltage gain. However, the voltage gain is still lower to meet the demand of high voltage gain. Moreover, the circuitry becomes complex and expensive.

This paper presents a novel class of high gain non-isolated dc-dc step up converters integrated with active and passive switched inductor networks. Proposed converters offer very high voltage gain at a small duty cycle i.e. duty cycle $<0.5$ which reduces the electromagnetic interference, reverse recovery problem and conduction loss of the switches. Moreover, a single control signal is used for all the switches which reduces the circuit operation complexity. The operating principle and the steady state analysis of the proposed converters are presented in details for equal inductances. Finally, the simulation results by PSIM 9.0 are provided to verify the analysis.

\section{TOPOLOGICAL DERIVATION OF PROPOSED CONVERTERS}

Figure 2 shows the active switched inductor (A-SL) and passive switched inductor (P-SL) networks presented in [23]-[24].

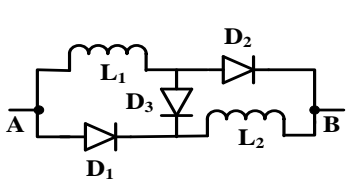

(a)

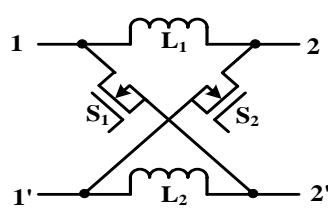

(b)

Figure 2. Switched inductor networks (a) passive switched inductor network (b) active switched inductor network

The passive switched inductor (P-SL) network consists of two inductors $\boldsymbol{L}_{\mathbf{1}}, \boldsymbol{L}_{\mathbf{2}}$ and three diodes $\boldsymbol{D}_{\mathbf{1}}$, $\boldsymbol{D}_{\mathbf{2}}$ and $\boldsymbol{D}_{\mathbf{3}}$. When the voltage difference across the terminals A and $\mathrm{B}\left(\boldsymbol{V}_{\boldsymbol{A} \boldsymbol{B}}\right)$ is positive, $\boldsymbol{D}_{\mathbf{1}}$ and $\boldsymbol{D}_{\mathbf{2}}$ become forward biased, and $\boldsymbol{D}_{\mathbf{3}}$ becomes reverse biased. As a result, inductors $\boldsymbol{L}_{\mathbf{1}}$ and $\boldsymbol{L}_{\mathbf{2}}$ are in parallel connection. When the voltage difference across the terminals A and B $\left(\boldsymbol{V}_{\boldsymbol{A} \boldsymbol{B}}\right)$ is negative, $\boldsymbol{D}_{\mathbf{1}}$ and $\boldsymbol{D}_{\mathbf{2}}$ become reverse biased, and $\boldsymbol{D}_{\mathbf{3}}$ becomes forward biased. This put the inductors $\boldsymbol{L}_{\mathbf{1}}$ and $\boldsymbol{L}_{\mathbf{2}}$ in series connection.

The active switched inductor (A-SL) network consists of two inductors $L_{1}, L_{2}$ and two switches $S_{1}$, $S_{2}$. Both of the switches operate simultaneously. When the switches $S_{1}$ and $S_{2}$ are turned on, inductors $L_{1}$ and 
$L_{2}$ become parallel connected. When they are turned off, inductors $L_{1}$ and $L_{2}$ become series connected across the input terminals $1-1$ ' of the two port network if a load is connected across the terminals 2-2'.

The proposed converters derived from [25] are obtained by applying the above A-SL and P-SL networks. The proposed converters are shown in Figure 3. The inductors in the P-SL and A-SL networks are of equal inductance. Power switches share the same switching signals which makes the control easy. When all the switches are turned on simultaneously, the inductors in the P-SL and A-SL networks operate in parallel connection and are charged by the power source, and when all the switches are turned off simultaneously, inductors operate in series connection and are discharged to load.



(a)



(b)

Figure 3. Proposed converters: (a) proposed converter with A-SL network (b) proposed converter combined with P-SL and A-SL networks

\section{OPERATION OF PROPOSED CONVERTERS}

\subsection{Operation of proposed converter with A-SL network}

The proposed converter with A-SL network in Figure 3(a) involves four inductors $\left(L_{1}, L_{2}, L_{3}\right.$ and $\left.L_{4}\right)$, three capacitors $\left(C_{1}, C_{2}\right.$ and $\left.C_{3}\right)$, four diodes $\left(D_{1}, D_{2}, D_{3}\right.$ and $\left.D_{4}\right)$ and five high frequency controlled switches $\left(S_{1}, S_{2}, S_{3}, S_{4}\right.$ and $\left.S_{5}\right)$. MOSFETs are used as the high frequency controlled switches and these are operated based on a single duty cycle. $V_{i}$ represents the low dc input voltage from PV source or fuel cell. The resistive load is connected across the capacitor $C_{3}$. The equivalent circuit in continuous conduction mode (CCM) operation is shown in Figure 4.

Mode 1 [0 to $\boldsymbol{D T}_{S}$ ]: All the five switches are turned on during this time interval. The equivalent circuit is shown in Figure 4(a). Inductors $L_{1}$ and $L_{2}$ are energized in parallel by the supply voltage $V_{i}$. Also, $L_{3}$ and $L_{4}$ are energized during this period. Capacitors $C_{1}, C_{2}$ and $C_{3}$ are discharged. All the diodes $D_{1}, D_{2}, D_{3}$ and $D_{4}$ are reverse biased. The load is supplied by the capacitor $C_{3}$. As $L_{1}$ and $L_{2}$ are in parallel connection, $v_{L 1}=v_{L 2}$. The voltages across the inductors $L_{1}, L_{2}, L_{3}$ and $L_{4}$ are expressed as:

$$
v_{L 1}=v_{L 2}=V_{i}, v_{L 3}=V_{C 1}, v_{L 4}=V_{C 2}+V_{C 3}
$$

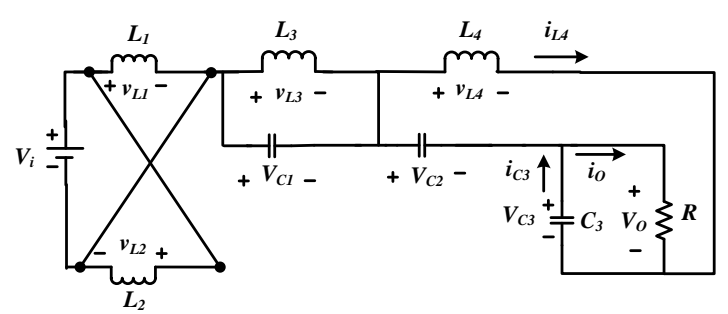

(a)

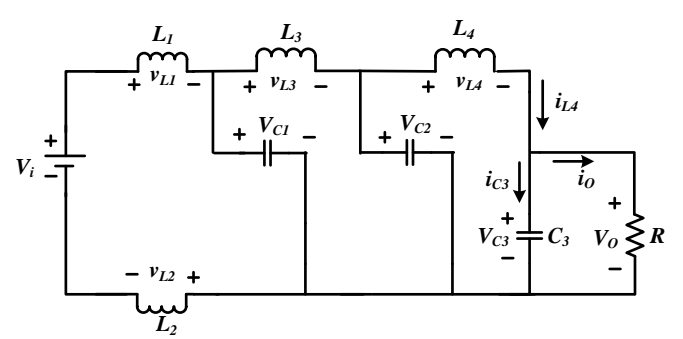

(b)

Figure 4. Equivalent circuit of proposed converter with A-SL network in CCM (a) when all the switches are on (b) when all the switches are off

Mode $2\left[\boldsymbol{D} \boldsymbol{T}_{\boldsymbol{S}} \boldsymbol{t o} \boldsymbol{T}_{\boldsymbol{S}}\right]$ : All the four switches are turned off during this time interval. The equivalent circuit is shown in Figure 4(b). Inductors $L_{1}$ and $L_{2}$ are discharged in series. Also, $L_{3}$ and $L_{4}$ are discharged. Capacitors $C_{1}, C_{2}$ and $C_{3}$ are charged by the inductors. All the diodes $D_{1}, D_{2}, D_{3}$ and $D_{4}$ are forward biased. The load is supplied by the inductor $L_{4}$. As an identical current flows through $L_{1}$ and $L_{2}, v_{L 1}=v_{L 2}$. The voltages across the inductors are expressed as: 


$$
v_{L 1}=\frac{V_{i}-V_{C 1}}{2}, v_{L 3}=V_{C 1}-V_{C 2}, v_{L 4}=V_{C 2}-V_{C 3}
$$

The volt-second balance of $v_{L 1}$ is given by,

Or,

$$
V_{i} D T_{S}=-\left[\frac{V_{i}-V_{C 1}}{2}\right](1-D) T_{S}
$$

$$
V_{C 1}=\frac{V_{i}(1+D)}{1-D}
$$

Similarly, volt-second balance of $v_{L 3}$ is given by,

Or,

$$
V_{C 1} D T_{S}=-\left(V_{C 1}-V_{C 2}\right)(1-D) T_{S}
$$

$$
V_{C 2}=\frac{V_{C 1}}{1-D}=\frac{V_{i}(1+D)}{(1-D)^{2}}
$$

Similarly, volt-second balance of $v_{L 4}$ is given by,

Or,

$$
\left(V_{C 2}+V_{C 3}\right) D T_{S}=-\left(V_{C 2}-V_{C 3}\right)(1-D) T_{S}
$$

$$
V_{C 3}=\frac{V_{C 2}}{1-2 D}=\frac{V_{i}(1+D)}{(1-D)^{2}(1-2 D)}=V_{O}
$$

Therefore, the voltage gain in Continuous Conduction Mode is:

$$
G_{C C M}=\frac{(1+D)}{(1-D)^{2}(1-2 D)}
$$

Voltage stress across the diodes are found as:

$$
\left\{\begin{array}{l}
V_{D 1}=V_{i}+V_{C 1} \\
V_{D 2}=V_{i}+V_{C 1}+V_{C 2} \\
V_{D 3}=V_{i}+V_{C 1}+V_{C 2}+V_{C 3} \\
V_{D 4}=V_{C 3}
\end{array}\right.
$$

Voltage stress across the switches are found as:

$$
\left\{\begin{array}{l}
V_{S 1}=V_{S 2}=\frac{V_{i}+V_{C 1}}{2} \\
V_{S 3}=V_{C 2} \\
V_{S 4}=V_{S 5}=V_{C 3}
\end{array}\right.
$$

The equivalent circuit in discontinuous conduction mode (DCM) is shown in Figure 5 and the analysis is given below.

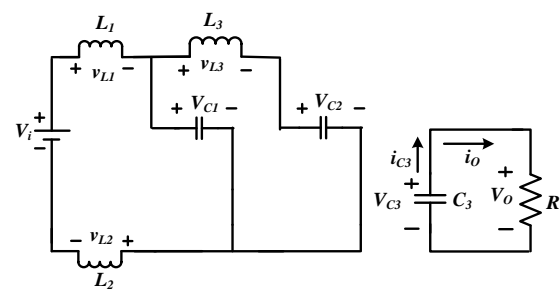

Figure 5. Equivalent circuit of proposed converter with A-SL network in DCM 
Mode 1 [0 to $\boldsymbol{D T}_{S}$ ]: This mode is similar to Mode 1 in CCM operation. During this time, the peak current $i_{L 4 P}$ through the inductor $L_{4}$ derived from Figure 6 is:

$$
i_{L 4 P}=\frac{V_{C 2}+V_{C 3}}{L_{4}} D T_{S}
$$

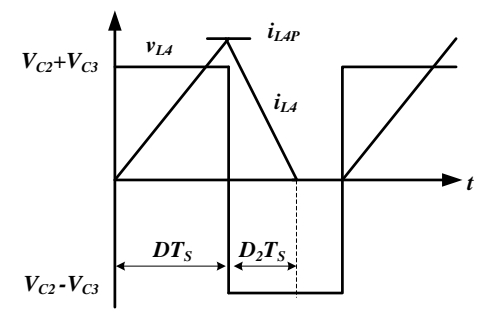

Figure 6. $v_{L 4}$ versus $i_{L 4}$ in DCM

Mode $2\left[\boldsymbol{D} \boldsymbol{T}_{\boldsymbol{S}}\right.$ to $\left.\left(\boldsymbol{D T} \boldsymbol{T}_{\boldsymbol{S}}+\boldsymbol{D}_{\mathbf{2}} \boldsymbol{T}_{\boldsymbol{S}}\right)\right]$ : This mode is similar to Mode 2 in CCM operation. During this time, the inductor current $i_{L 4}$ is decreased to zero. The peak current through the inductor $L_{4}$ can be derived from Figure 6 as:

$$
i_{L 4 P}=\frac{V_{C 3}-V_{C 2}}{L_{4}} D_{2} T_{S}
$$

Mode $3\left[\left(\boldsymbol{D} \boldsymbol{T}_{S}+\boldsymbol{D}_{2} \boldsymbol{T}_{S}\right)\right.$ to $\left.\boldsymbol{T}_{S}\right]$ : During this time interval, the equivalent circuit is shown in Figure 5 when the load is supplied by the capacitor $C_{3}$. Combining (9) and (10), $D_{2}$ can be expressed as:

$$
D_{2}=\left[\frac{V_{i}(1+D)+V_{O}(1-D)^{2}}{V_{O}(1-D)^{2}-V_{i}(1+D)}\right] D
$$

The average current through the diode $D_{4}$ is equal to the average load current, therefore:

Or,

$$
\frac{\frac{1}{2} \times D_{2} T_{S} \times i_{L 4 P}}{T_{S}}=I_{O}=\frac{V_{O}}{R}
$$

$$
V_{O}=\frac{D 2^{2} V_{C 2}}{D 2^{2}-2 \tau}
$$

where $\tau=\frac{L_{4}}{R T_{S}}=$ time constant of $L_{4}$. Now, if $V_{C 2}=\frac{V_{i}(1+D)}{(1-D)^{2}}$ is put in (12), then $D_{2}$ is deduced as:

$$
D_{2}=\sqrt{\frac{2 \tau V_{O}(1-D)^{2}}{V_{O}(1-D)^{2}-V_{i}(1+D)}}
$$

Again, the volt-second balance of $v_{L 4}$ is given by,

Or,

$$
\left(V_{C 2}+V_{C 3}\right) D T_{S}=-\left(V_{C 2}-V_{C 3}\right) D_{2} T_{S}
$$

$$
\frac{V_{C 3}}{V_{i}}=\frac{\left(D+D_{2}\right)(1+D)}{\left(D_{2}-D\right)(1-D)^{2}}
$$

Thus, the voltage gain in DCM is:

$$
G_{D C M}=\frac{V_{C 3}}{V_{i}}=\frac{\left(D+D_{2}\right)(1+D)}{\left(D_{2}-D\right)(1-D)^{2}}
$$

The boundary condition arises when $i_{L 4}$ decreased to zero at $T_{S}$. At boundary condition, $D_{2}=(1-$ $D)$. Now, if we put $V_{C 2}=V_{C 3}(1-2 D)$, then the time constant of $L_{4}$ at boundary condition derived from equation (13) is given by, 


$$
\tau_{B}=D(1-D)^{2}
$$

The relationship between $\tau_{B}$ and $D$ is shown in Figure 7. When $\tau>\tau_{B}$, the converter operates in CCM and when $\tau<\tau_{B}$, the converter operates in DCM.



Figure 7. Boundary condition of the converter

\subsection{Operation of proposed converter combined with P-SL and A-SL network}

The proposed converter in Figure 3(b) involves six inductors $\left(L_{1 a}, L_{1 b}, L_{2 a}, L_{2 b}, L_{3}\right.$ and $\left.L_{4}\right)$, three capacitors $\left(C_{1}, C_{2}\right.$ and $\left.C_{3}\right)$, ten diodes $\left(D_{1 a}, D_{1 b}, D_{1 c}, D_{2 a}, D_{2 b}, D_{2 c}, D_{3}, D_{4}, D_{5}\right.$ and $\left.D_{6}\right)$ and five high frequency controlled switches $\left(S_{1}, S_{2}, S_{3}, S_{4}\right.$ and $\left.S_{5}\right)$. The operation in CCM is shown in Figure 8.

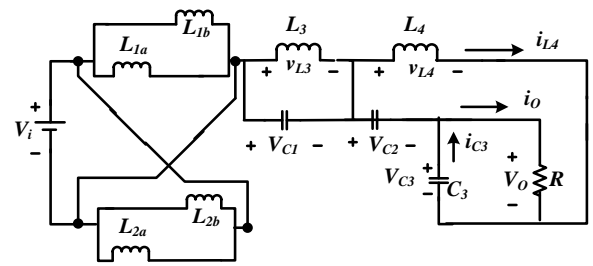

(a)



(b)

Figure 8. Equivalent circuit in CCM of proposed converter combined with A-SL and P-SL networks (a) when all the switches are on (b) when all the switches are off

Mode $1\left[0\right.$ to $\boldsymbol{D T}_{S}$ ]: All the four switches are turned on during this time interval. The equivalent circuit is shown in Figure 8(a). Inductors $L_{1 a}, L_{1 b}, L_{2 a}$ and $L_{2 b}$ are energized in parallel by the supply voltage $V_{i}$. Also, $L_{3}$ and $L_{4}$ are energized. Diodes $D_{1 a}, D_{1 b}, D_{2 a}$ and $D_{2 b}$ are forward biased and the rest of the diodes are reverse biased. The load is supplied by the capacitor $C_{3}$. As $L_{1 a}, L_{1 b}, L_{2 a}$ and $L_{2 b}$ are in parallel connection, $v_{L 1 a}=v_{L 1 b}=v_{L 2 a}=v_{L 2 b}$. Now, if it is assumed that $v_{L 1 a}=v_{L 1 b}=v_{L 2 a}=v_{L 2 b}=v_{L 1}$, then the voltages across the inductors $L_{1 a}, L_{1 b}, L_{2 a}, L_{2 b}, L_{3}$ and $L_{4}$ are expressed as:

$$
\left\{\begin{array}{l}
v_{L 1 a}=v_{L 1 b}=v_{L 2 a}=v_{L 2 b}=v_{L 1}=V_{i} \\
v_{L 3}=V_{C 1} \\
v_{L 4}=V_{C 2}+V_{C 3}
\end{array}\right.
$$

Mode $2\left[\boldsymbol{D T} \boldsymbol{T}_{\boldsymbol{S}}\right.$ to $\left.\boldsymbol{T}_{\boldsymbol{S}}\right]$ : During this time interval, all the switches are off. The equivalent circuit is shown in Figure 8(b). The diodes $D_{1 a}, D_{1 b}, D_{2 a}$ and $D_{2 b}$ are reverse biased and rest of the diodes are forward biased. Inductors $L_{1 a}, L_{1 b}, L_{2 a}$ and $L_{2 b}$ are discharged in series and energize capacitors $C_{1}, C_{2}$ and $C_{3}$. Also, the inductors $L_{3}$ and $L_{4}$ are discharged to $C_{2}$ and $C_{3}$. The load is supplied by the inductor $L_{4}$. Due to identical current flows through $L_{1 a}, L_{1 b}, L_{2 a}$ and $L_{2 b}, v_{L 1 a}=v_{L 1 b}=v_{L 2 a}=v_{L 2 b}$. Now, if it is assumed that $v_{L 1 a}=v_{L 1 b}=v_{L 2 a}=v_{L 2 b}=v_{L 1}$, then the voltages across the inductors $L_{1 a}, L_{1 b}, L_{2 a}, L_{2 b}, L_{3}$ and $L_{4}$ are expressed as:

$$
\left\{\begin{array}{l}
v_{L 1 a}=v_{L 1 b}=v_{L 2 a}=v_{L 2 b}=v_{L 1}=\frac{V_{i}-V_{C 1}}{4} \\
v_{L 3}=V_{C 1}-V_{C 2} \\
v_{L 4}=V_{C 2}-V_{C 3}
\end{array}\right.
$$


The volt-second balance of $v_{L 1}$ is given by,

Or,

$$
V_{i} D T_{S}=-\left[\frac{V_{i}-V_{C 1}}{4}\right](1-D) T_{S}
$$

$$
V_{C 1}=\frac{V_{i}(1+3 D)}{1-D}
$$

Similarly, volt-second balance of $v_{L 3}$ is given by,

Or,

$$
V_{C 1} D T_{S}=-\left(V_{C 1}-V_{C 2}\right)(1-D) T_{S}
$$

$$
V_{C 2}=\frac{V_{C 1}}{1-D}=\frac{V_{i}(1+3 D)}{(1-D)^{2}}
$$

Similarly, volt-second balance of $v_{L 4}$ is given by,

Or,

$$
\left(V_{C 2}+V_{C 3}\right) D T_{S}=-\left(V_{C 2}-V_{C 3}\right)(1-D) T_{S}
$$

$$
V_{C 3}=\frac{V_{C 2}}{1-2 D}=\frac{V_{i}(1+3 D)}{(1-D)^{2}(1-2 D)}=V_{O}
$$

Thus, the voltage gain in continuous conduction mode is,

$$
G_{C C M}=\frac{(1+3 D)}{(1-D)^{2}(1-2 D)}
$$

Voltage stress across the diodes are found as:

$$
\left\{\begin{array}{l}
V_{D 1 c}=V_{D 2 c}=V_{i} \\
V_{D 3}=V_{i}+V_{C 1} \\
V_{D 4}=V_{i}+V_{C 1}+V_{C 2} \\
V_{D 5}=V_{i}+V_{C 1}+V_{C 2}+V_{C 3}
\end{array}\right.
$$

Voltage stress across the switches are found as:

$$
\left\{\begin{array}{l}
V_{S 1}=V_{S 2}=\frac{V_{i}+V_{C 1}}{2} \\
V_{S 3}=V_{C 2} \\
V_{S 4}=V_{S 5}=V_{C 3} \\
V_{D 1 a}=V_{D 1 b}=V_{D 2 a}=V_{D 2 b}=\frac{V_{C 1}-V_{i}}{4}
\end{array}\right.
$$

The equivalent circuit in DCM is given in Figure 9. The analysis of DCM is similar to that of the analysis of DCM of the proposed converter with A-SL network.

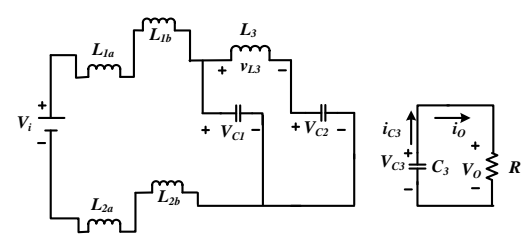

Figure 9. Equivalent circuit of proposed converter combined with A-SL and P-SL network in DCM

If $V_{C 2}=\frac{V_{i}(1+3 D)}{(1-D)^{2}}$ is put in (12), then $D_{2}$ is deduced as: 


$$
D_{2}=\sqrt{\frac{2 \tau V_{O}(1-D)^{2}}{V_{O}(1-D)^{2}-V_{i}(1+3 D)}}
$$

Again, the volt-second balance of $v_{L 4}$ is given by,

Or,

$$
\left(V_{C 2}+V_{C 3}\right) D T_{S}=-\left(V_{C 2}-V_{C 3}\right) D_{2} T_{S}
$$

$$
\frac{V_{C 3}}{V_{i}}=\frac{\left(D+D_{2}\right)(1+3 D)}{\left(D_{2}-D\right)(1-D)^{2}}
$$

Therefore, the voltage gain in DCM is:

$$
G_{D C M}=\frac{V_{C 3}}{V_{i}}=\frac{\left(D+D_{2}\right)(1+3 D)}{\left(D_{2}-D\right)(1-D)^{2}}
$$

Boundary condition of this proposed converter is also similar to that of the A-SL converter. If we put $D_{2}=1-D$ and $V_{C 2}=V_{C 3}(1-2 D)$, then the time constant of $L_{4}$ at boundary condition derived from equation (24) is given by,

$\tau_{B}=D(1-D)^{2}$

Thus, it is observed that the time constant is equal to the time constant of the proposed converter with A-SL network.

\section{ANALYSIS OF THE PROPOSED CONVERTERS}

The analysis of the proposed converters is performed based on voltage gain, voltage stress across the switches and diodes, inductor time constant at boundary condition and the number of passive elements. Table 1 shows the comparison between the proposed converters, the conventional boost converter and the converter presented in [27].

From Table 1 it is observed that in CCM the voltage gains of the proposed converters are much higher than that of the conventional boost converter and the converter in [27]. Among the four converters, combined A-SL and P-SL converter gives the highest voltage gain. Inductor time constants at boundary condition in the proposed converters are identical and higher than the other converters for a certain value of duty cycle. This helps the converter not to go in the discontinuous conduction mode. Moreover, the

\begin{tabular}{|c|c|c|c|c|}
\hline & A-SL Converter & $\begin{array}{c}\text { Combined A-SL } \\
\text { and P-SL converter }\end{array}$ & $\begin{array}{c}\text { Conventional } \\
\text { Boost Converter }\end{array}$ & Converter in [27] \\
\hline Voltage gain in CCM & $\frac{(1+D)}{(1-D)^{2}(1-2 D)}$ & $\frac{(1+3 D)}{(1-D)^{2}(1-2 D)}$ & $\frac{1}{1-D}$ & $\frac{1+3 D}{(1-D)}$ \\
\hline Duty cycle range & $0<D<0.5$ & $0<D<0.5$ & $0<D<1$ & $0<D<1$ \\
\hline No. of Diode & 4 & 10 & 1 & 7 \\
\hline No. of Capacitor & 3 & 3 & 1 & 1 \\
\hline No. of Inductor & 5 & 7 & 1 & 4 \\
\hline $\begin{array}{l}\text { Maximum voltage stress } \\
\text { across switches }\end{array}$ & $\begin{array}{c}\frac{V_{i}(1+D)}{(1-D)^{2}(1-2 D)} \\
\text { across } S_{4} \text { and } S_{5}\end{array}$ & $\begin{array}{c}\frac{V_{i}(1+3 D)}{(1-D)^{2}(1-2 D)} \\
\text { across } S_{4} \text { and } S_{5}\end{array}$ & $\frac{1}{1-D}$ & $\begin{array}{c}\frac{V_{i}(1+D)}{(1-D)} \\
\text { across } S_{1} \text { and } S_{2}\end{array}$ \\
\hline $\begin{array}{l}\text { Maximum voltage stress } \\
\text { across diodes }\end{array}$ & $\begin{array}{c}V_{i}+\frac{V_{i}(1+D)}{1-D}+ \\
\frac{V_{i}(1+D)}{(1-D)^{2}}+\frac{V_{i}(1+D)}{(1-D)^{2}(1-2 D)} \\
\text { across the diode } D_{3}\end{array}$ & $\begin{array}{c}V_{i}+\frac{V_{i}(1+3 D)}{1-D}+ \\
\frac{V_{i}(1+3 D)}{(1-D)^{2}}+ \\
\frac{V_{i}(1+3 D)}{(1-D)^{2}(1-2 D)}\end{array}$ & $\frac{1}{1-D}$ & $\frac{2 V_{i}(1+D)}{(1-D)}$ \\
\hline $\begin{array}{l}\text { Inductor Time constant } \\
\text { at boundary condition }\end{array}$ & $D(1-D)^{2}$ & $\begin{array}{l}\text { across the diode } D_{5} \\
D(1-D)^{2}\end{array}$ & $D(1-D) / 2$ & $\frac{D(1-D)^{2}}{2(1+3 D)}$ \\
\hline
\end{tabular}
electromagnetic interference, reverse recovery problem and the conduction loss at the switches in the proposed converters are reduced due to smaller duty cycle.

Table 1. Contrast between the proposed converters, conventional boost converter and the converter in [27] 
However, the voltage stress across the diodes and switches in the proposed converters are higher than that of the conventional boost converter and the converter in [27]. The combined A-SL and P-SL converter suffers the highest voltage stresses across the diode $D_{5}$ and switches $S_{4}$ and $S_{5}$. Hence, the voltage ratings of these components should be higher than the other components. Moreover, the proposed converters involve more components. Therefore, if the required voltage gain is not that much high, then the proposed ASL converter is preferred to the combined A-SL and P-SL converter because it involves lower number of components. But if an extremely high voltage gain is required, then the combined A-SL and P-SL converter is preferred to the A-SL converter.

\section{SIMULATION RESULTS}

The proposed converters are designed and implemented by using PSIM 9.0. The values of different circuit parameters and components taken for the simulation are tabulated in Table 2. Mathematical calculations of the output voltages are done from (5) and (20), and these are found to be $262.46 \mathrm{~V}$ and 403.95 $\mathrm{V}$. The simulation gives the values of output voltages very near to the calculated values with a negligible ripple content which is within prescribed tolerable limit [26]. The ripple content is controlled by controlling the value of $\boldsymbol{C}_{3}$. The output voltages are shown in Figure 10.

Table 2. Values of different parameters and components taken for simulation

\begin{tabular}{lclc}
\hline Parameters/components & Value & Parameters/components & Value \\
\hline Input voltage $\left(V_{i}\right)$ & $20 \mathrm{~V}$ & Capacitor $\left(C_{1}\right)$ & $1000 \mu \mathrm{F}$ \\
Switching Frequency $\left(f_{S}\right)$ & $10 \mathrm{kHz}$ & Capacitor $\left(C_{2}\right)$ & $1000 \mu \mathrm{F}$ \\
Inductors in A-SL and P-SL networks & $1 \mathrm{mH}$ & Capacitor $\left(C_{3}\right)$ & $1000 \mu \mathrm{F}$ \\
Inductor $\left(L_{3}\right)$ & $3 \mathrm{mH}$ & Load across $C_{3}$ & $100 \Omega$ \\
Inductor $\left(L_{4}\right)$ & $5 \mathrm{mH}$ & Duty Cycle $(D)$ & 0.369 \\
\hline
\end{tabular}

In both of the converters maximum voltage stress occurs across the switches $S_{4}$ and $S_{5}$ and are found from (8) and (23). These are found as $262.46 \mathrm{~V}$ in A-SL converter and $403.95 \mathrm{~V}$ in combined A-SL and P-SL converter respectively. The simulation shows the values very near to the calculated values which are shown in Figure 11.



(a)



(b)

Figure 10. Output voltages of proposed (a) A-SL converter (b) combined A-SL and P-SL converter


Figure 11. Voltage across switch $S_{5}$ of (a) A-SL converter (b) Combined A-SP and P-SL converter 


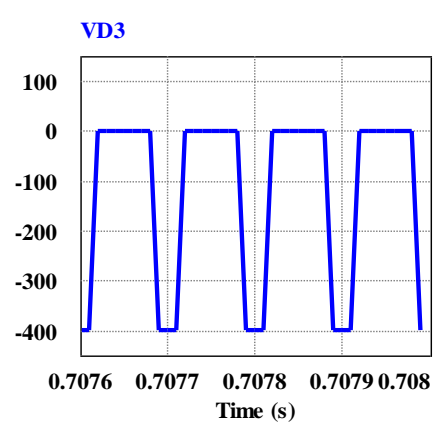

(a)

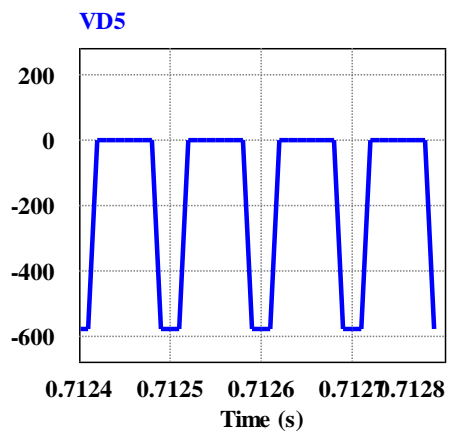

Figure 12. Voltage across (a) $D_{3}$ in A-SL converter (b) $D_{5}$ in combined A-SL and P-SL converter

The maximum voltage stress across the diodes appear across $D_{3}$ and $D_{5}$ in A-SL converter and combined A-SL and P-SL converter respectively. Equations (7) and (22) give the voltage across $D_{3}$ as 394.62 $\mathrm{V}$ and voltage across $D_{5}$ as $596.57 \mathrm{~V}$ respectively. Calculated values are very near to the simulated values and are depicted in Figure 12.

\section{CONCLUSION}

This paper has presented a class of very high gain dc-dc step up converters based on active and passive switched inductor networks. The proposed converters have several novel characteristics. Both of the converters can achieve a very high voltage gain with a small duty cycle i.e. duty cycle less than 0.5 which is nearly impossible for conventional boost converter. Higher inductor time constant at boundary condition assures the converters' operation in continuous conduction mode. The electromagnetic interference problem depending upon the rate of change of current through the switch, and the conduction loss of the switch are reduced due to smaller duty cycle. The current stress of the inductors and voltage stress of the switches are reduced by the use of passive switched inductor networks and active switched inductor network respectively. What's more, the control complexity is reduced greatly as a single control signal is used for all switches. These characteristics makes it evident that the proposed converters are really suitable for the applications where an extreme voltage gain is required.

\section{REFERENCES}

[1] J. Leyva-Ramos, J. M. Lopez-Cruz, M. G. Ortiz Lopez, L. H. Diaz-Saldierna. Switching regulator using a high stepup voltage converter for fuel-cell modules. IET Power Electronics. 2013; 6(8): 1626-1633.

[2] G. Velasco-Quesada, F. Guinjoan-Gispert, R. Piqué-López, M. Román-Lumbreras, A. Conesa-Roca. Electrical PV array reconfiguration strategy for energy extraction improvement in grid-connected PV systems. IEEE Trans. on Industrial Electronics. 2009; 56(11): 4319-4331.

[3] K. Tseng, C. Huang. High step-up high-efficiency interleaved converter with voltage multiplier module for renewable energy system. IEEE Trans. on Industrial Electronics. 2014; 61(3): 1311-1319.

[4] C. Young, M. Chen, T. Chang, C. Ko, K. Jen. Cascade Cockcroft-Walton voltage multiplier applied to transformerless high step-up dc-dc converter. IEEE Trans. on Industrial Electronics, 2013; 60(2): 523-537.

[5] Ahmad Saudi Samosir, Taufiq, Abd Jaafar Shafie, Abdul Halim Mohd Yatim. Simulation and Implementation of Interleaved Boost DC-DC Converter for Fuel Cell Application. International Journal of Power Electronics and Drive Systems. 2011; 1(2): 168-174.

[6] Khandker Tawfique Ahmed, Mithun Datta, Nur Mohammad. A Novel Two Switch Non-inverting Buck-Boost Converter based Maximum Power Point Tracking System. International Journal of Power Electronics and Drive Systems. 2013; 3(4): 467-477.

[7] C. T. Pan, C. M. Lai. A High-Efficiency High Step-Up Converter with Low Switch Voltage Stress for Fuel-Cell System Applications. IEEE Trans. on Inustrial Electronics. 2010; 57(6): 1998-2006.

[8] H. M. Hsu, C. T. Chien. Multiple Turn Ratios of On-Chip Transformer with Four Intertwining Coils. IEEE Trans. on Electron Devices. 2014; 61(1): 44-47.

[9] X. Zhang, C. C. Yao, C. Li, L. X. Fu, F. Guo, J. Wang. A Wide Bandgap Device-Based Isolated Quasi-SwitchedCapacitor DC/DC Converter. IEEE Trans. on Power Electronics. 2014; 29(5): 2500-2510.

[10] B. Gu, J. Dominic, J. S. Lai, Z. Zhao, C. Liu. High Boost Ratio Hybrid Transformer DC-DC Converter for Photovoltaic Module Applications. IEEE Trans. on Power Electronics. 2013; 28(4): 2048-2058. 
[11] H. S. Kim, J. W. Baek, M. H. Ryu, J. H. Kim, J. H. Jung. The High-Efficiency Isolated AC-DC Converter Using the Three-Phase Interleaved LLC Resonant Converter Employing the Y-Connected Rectifier. IEEE Trans. on Power Electronics. 2014; 29(8): 4017-4028.

[12] M. Sarhangzadeh, S. H. Hosseini, M. B. B. Sharifian, G. B. Gharehpetian. Multi input Direct DC-AC Converter with High-Frequency Link for Clean Power-Generation Systems. IEEE Trans. on Power Electronics. 2011; 26(6): 1777-1789.

[13] P. H. Tseng, J. F. Chen, Y. P. Hsieh. A novel active clamp high step-up DC-DC converter with coupled-inductor for fuel cell system. $1^{\text {st }}$ International Future Energy Electronics Conference. 2013; 1: 326-331.

[14] Y. H. Hu, W. D. Xiao, W. H. Li, X. N. He. Three-phase interleaved high-step-up converter with coupled-inductorbased voltage quadrupler. IET Power Electronics. 2014; 7(7): 1841-1849.

[15] Y. Zhao, W. H. Li, X. N. He. Single-Phase Improved Active Clamp Coupled-Inductor-Based Converter with Extended Voltage Doubler Cell. IEEE Trans. on Power Electronics. 2012; 27(6); 2869-2878.

[16] T. Meng, S. Yu, H. Q. Ben, G. Wei. A Family of Multilevel Passive Clamp Circuits with Coupled Inductor Suitable for Single-Phase Isolated Full-Bridge Boost PFC Converter. IEEE Trans. on Power Electronics.2014; 29(8): 43484356.

[17] Y. P. Hsieh, J. F. Chen, T. J. Liang, L. S. Yang. Novel High Step-Up DC-DC Converter with Coupled-Inductor and Switched-Capacitor Techniques. IEEE Trans. on Industrial. Electronics. 2012; 59(2); 998-1007.

[18] J. H. Lee, T. J. Liang, J. F. Chen. Isolated Coupled-Inductor-Integrated DC-DC Converter with Non-dissipative Snubber for Solar Energy Applications. IEEE Trans. on Industrial Electronics. 2014; 61(7): 3337-3348.

[19] J. Lei, Z. Xi, C. L. Yin, M. Chris, S. Q. Li, M. Y. Zhang. A novel soft-switching bidirectional DC-DC converter with coupled inductors. $28^{\text {th }}$ IEEE Applied Power Electronics Conference and Expositions. 2013; 1: 3040-3044.

[20] K. Umetani, S. Arimura, T. Hirano, J. Imaoka, M. Yamamoto. Evaluation of the Lagrangian method for deriving equivalent circuits of integrated magnetic components: A case study using the integrated winding coupled inductor. IEEE Energy Conversion Congress and Exposition. 2013; 1: 495-502.

[21] F. Yang, X. B. Ruan, Y. Yang, Z. H. Ye. Interleaved Critical Current Mode Boost PFC Converter With Coupled Inductor. IEEE Trans.on Power Electronics. 2011; 26(9): 2404-2413.

[22] B. R. Lin, J. J. Chen. Analysis and implementation of a soft switching converter with high-voltage conversion ratio. IET Power Electronics. 2008; 1(3): 386-394.

[23] L. S. Yang, T. J. Liang, J. F. Chen. Transformer less DC-DC Converters With High Step-Up Voltage Gain. IEEE Trans. on Industrial Electronics. 2009; 56(8): 3144-3152.

[24] Y. Axelrod, Berkovich, A. Ioinovici. Switched-capacitor/switched-inductor structures for getting transformer less hybrid DC-DC PWM converters. IEEE Trans. on Circuits Systems I: Regular Papers. 2008; 55(2): 687-696.

[25] M Al Mamun, G. Sarowar, M A Hoque. A Novel High Gain DC-DC Step up Converter. American Journal of Engineering Research. 2016; 5(7): 106-111.

[26] Ned Mohan. Power Electronics: A First Course. John Wiley \& Sons, Inc., Wiley. 2012

[27] Yu Tang, Dongjin Fu, Ting Wang, Zhiwei Xu. Hybrid Switched-Inductor Converters for High Step-Up Conversion. IEEE Trans. on Industrial Electronics. 2015; 62(3): 1480-1490. 